\title{
PESQUISAS PARA UNA NUEVA LECTURA DE LOS NAUFRAGIOS, DE ALVAR NUÑEZ CABEZA DE VACA
}

\author{
P O R
}

ENRIQUE PUPO-WALKER

Vanderbilt University

Al estimar la significación histórica de los Naufragios (1542) se ha sugerido, en estudios recientes, que el texto de Alvar Núñez representa una inversión del proyecto imperial y conquistador que España iniciaba en las primeras décadas del siglo xvi. Más aún: se ha subrayado, entre otras cosas, que los Naufragios ejemplifican el «discurso del fracaso» ${ }^{1}$. Es evidente que buena parte de lo que Cabeza de Vaca relata no es equiparable a un enunciado triunfalista ${ }^{2}$; y es igualmente cierto que los ajustes que Cabeza de Vaca y los suyos hacen para sobrevivir son los que esperaríamos de individuos pertenecientes a una cultura subyugada y en plena fase receptora ${ }^{3}$. En esos y otros órdenes se pro-

1 Véase Beatriz Pastor, Discurso narrativo de la conquista de América (La Habana: Casa de las Américas, 1983), p. 263. Para un análisis minucioso de los componentes retóricos de ese discurso, consúltese Roberto González Echevarría, The Narrative of America (Cambridge: Cambridge University Press, que en breve se publicará); Walter Mignolo, "Cartas, crónicas y relaciones del descubrimiento y la conquista», en Historia de la literatura hispanoamericana: época colonial, Ed. Luis Iñigo Madrigal (Madrid: Ediciones Cátedra. 1982), pp. 57-116, y Stephanie Merrim, "Historia y escritura en las crónicas de Indias: ensayo de un método», en Explicación de textos literarios, IX, núm. 2 (1981), pp. 193-200; y de la misma autora: «Auto-bio-graphy, History, and Cortés' Segunda Carta-Relación», de próxima aparición en Dispositio (University of Michigan, Ann Arbor).

2 En contraste con otros - notablemente Colón-, Alvar Núñez no trata de compensar la pobreza de la Florida y otras áreas por medio de narraciones hiperbólicas, como sí lo hizo el Inca Garcilaso en su Florida (II, I, Cap. XXVI; V, I, Cap. VIII). Su capacidad para relatar simplemente lo que vio es excepcional en muchos órdenes, acaso porque él llegó a la relación histórica con el austero equipo forense de un funcionario; y cabe especular que tal vez narró los hechos de ese modo para compensar la notable proyección autobiográfica que adquiere su relato.

3 La tradicional distinción antropológica entre cultura donante y receptora es muy discutible en el contexto de los Naufragios, ya que Núñez, en particular, 
ducen inversiones en la narración que obviamente no eran las habituales en las relaciones que describen la exploración y conquista del Nuevo Mundo ${ }^{4}$. Pero aunque deben reconocerse esas peculiaridades del texto, creo que leer los Naufragios, en su totalidad, como una subtipología centrada en el "discurso del fracaso» equivale a una polarización excesiva del texto. Verlo así nos induciría a una caracterización parcial de la obra en la que no reconoceríamos las complejas y muy diversas filiaciones que exhiben los Naufragios. Estimo, además, que una inspección detenida del material biográfico sobre y en torno a Cabeza de Vaca no revela, en ningún momento, un desacuerdo significativo, entre las líneas generales de su pensamiento y el marco de valores e instituciones que consolidó la Corona española en el siglo XVI ${ }^{5}$.

En todo caso, esas y otras valoraciones son muestras recientes del diálogo crítico que reiteradamente han suscitado los Naufragios ${ }^{6}$. Pero

supera esa fase receptora al hacerse mercader y curandero en las costas del Golfo de México. En ese y otros sentidos su función se hace predominantemente transmisora.

4 También debe señalarse que tanto Fernández de Oviedo en su Historial general y natural de las Indias (1851), Ed. de Juan Pérez de Tudela (Madrid, B.A.E., 1959), IV, p. 290, y el mismo Inca Garcilaso, en sus Comentarios reales (II, II, Cap. XXIV), narran en protesta, o imaginativamente, varios episodios infortunados para las tropas españolas, sin que por ello se ponga en duda el mérito intrínseco de la conquista o su inevitable triunfo. Todas las citas de Oviedo provienen de esta edición. Entiéndase aquí por relación el informe, de índole forense, que a menudo requerían las autoridades virreinales, el Consejo de Indias y otras instituciones oficiales.

5 No hay evidencia histórica de un rechazo ideológico o institucional por parte de Núñez, ni siquiera en los últimos precarios años de su vida, cuando litigaba vigorosamente contra las injusticias que le impuso el Consejo de Indias. Véanse Morris Bishop, The Odyssey of Cabeza de Vaca (New York: The Century Co., 1933), pp. 270-293, y Samuel Eliot Morrison, The European Discovery of America: The Southern Voyages (1492-1616) (New York: Oxford University Press, 1974), pp. 569-580. A pesar de sus excesos, la obra de Bishop sigue siendo la mejor biografía de Cabeza de Vaca. Hay que destacar, por otra parte, que los datos a que se atiene Bishop ponen en evidencia una lectura defectuosa del texto de Núñez.

6 Varios estudios recientes ejemplifican ese elevado nivel de diálogo crítico sobre los Naufragios; diálogo que combina, en proporciones desiguales, pesquisas históricas y literarias. Destacan entre otros, David Boast, «The Naufragios of Alvar Núñez Cabeza de Vaca: A Case of Historical Romance», en South Eastern Latinamericanist, II (1983), pp. 3-12; Robert Lewis, «Los Naufragios de Alvar Núñez: historia y ficción», en Revista Iberoamericana, núm. 120-121 (1982), pp. 681694; Pedro Lastra, "Espacios de Alvar Núñez: las transformaciones de una escritura», en Cuadernos Americanos, CCLIV, núm. 3 (1984), pp. 150-163; Sylvia Molloy, «Formulación del yo en los Naufragios de Alvar Núñez Cabeza de Vaca», en Actas 
en estas notas, y sin tiempo para más, he de referirme principalmente, como punto de partida, al admirable estudio que sobre el texto de Cabeza de Vaca ha escrito el hispanista francés Jacques Lafaye ${ }^{7}$. Después de llevar a cabo un amplio repaso de textos históricos y otros documentos, Lafaye nos demuestra que la reputación de milagrero que se le ha imputado a Cabeza de Vaca emana originalmente de exageraciones y pasajes legendarios que, con propósitos disímiles, redactaron historiadores de Indias y comentaristas desde el siglo xvI al $\mathrm{xx}^{8}$. Las conclusiones a que llega Lafaye no me parecen discutibles; no obstante, mi propósito en estas páginas es explicitar por qué sectores de la narración de Núñez fueron leídos de esa manera; en otros términos: lo que me interesa destacar (desde una perspectiva casi arqueológica) son las codificaciones que subyacen en los Naufragios y que a su vez hicieron posible que el texto se describiera como una crónica milagrera del Medievo ${ }^{9}$. Con esas miras, mi lectura se acoge a un caudal amplio de información histórica, para examinar, desde ella, los Naufragios como «escritura» portadora de códigos disímiles que pueden trascender la

del Séptimo Congreso de la Asociación Internacional de Hispanistas, II (Roma, 1982), pp. 761-766; Luisa Pranzetti, "Il Naufragio come metafora», en Literatura de América, Vol. I, núm. I (1980), pp. 5-28; César A. Salgado, «De utopía a naufragio: hacia una hermenéutica antropológica de las crónicas de la conquista» (Monografía aún inédita, preparada en el Departamento de Literatura Comparada, Yale University, 1986). Valioso es el estudio de Antonio Carreño, «Naufragios, de Alvar Núñez Cabeza de Vaca: una retórica de la crónica colonial», que se publica en esta misma revista (pp. 499-516).

7 «Les miracles D'Alvar Núñez Cabeza de Vaca (1527-1536)», Bulletin Hispanique, LXIV (1962), pp. 136-153. Con el mismo título se ha traducido al castellano en Mesías, cruzadas, utopías: el judeo-cristianismo en las sociedades ibéricas (Mér. xico: Fondo de Cultura, 1984), pp. 65-84.

8 Véase Antonio Adroíno, Examen apologético de la histórica narración de los naufragios, peregrinaciones, i milagros de Alvar Núñez Cabeza de Vaca, en las tierras de la Florida $i$ del Nuevo México (sic) (Madrid: Imprenta de Juan de Zúñiga, 1736), p. 50. Véase también Carlos Lacalle, Noticia sobre Alvar Núñez Cabeza de Vaca: hazañas americanas de un caballero andaluz (Madrid: Instituto de Cultura Hispánica, 1961), pp. 10-32, y Darío Fernández Flores, Drama y aventura de los españoles en Florida (Madrid: Cultura Hispánica, 1963), pp. 37-87. En estos estudios se proyecta exageradamente la imagen evangelizadora de Cabeza de Vaca, así como su aparente aura de santidad.

9 Lafaye enumera los historiadores, sobre todo del siglo $\mathrm{XvI}$, que propagaron esa imagen de Alvar Núñez, «Los milagros...», pp. 65-83. A los autores citados por Lafaye habría que agregar muchos otros. Entre ellos: Juan de Grijalva, Vicente de Aguila y Pablo Beaumont. Para otros datos en torno a la reputación de Cabeza de Vaca véase W. Hodge, Spanish Explorers in Southern United States 1528-1543 (New York: C. Scribners' and Sons, 1907), pp. 26-82. 
proyección individualizada que Núñez otorga a su narración ${ }^{10}$. Pienso que una lectura de esa índole nos permitirá comprender con mayor claridad la organización retórica del texto así como la relevancia histórica y cultural que esa información posee.

Importa reconocer, de entrada, que los Naufragios se escribieron a posteriori; años después de la aventura y como resultado de varias redacciones. Además, el texto fue compuesto en circunstancias que permitían reflexiones pausadas sobre la fracasada expedición de Narváez, y sobre los descalabros que padecieron los tres españoles y el marroquí que a la postre sobrevivirían aquella azorante andanza ${ }^{11}$. También es necesario subrayar que, una vez llegados a Nueva España, Cabeza de Vaca se reconocerá como portador de noticias sin precedentes. Tan espectaculares fueron sus testimonios que las autoridades virreinales en breve pusieron en marcha, y sin demora, otras expediciones que debían ubicar las siete fabulosas ciudades de Cíbola que entonces se suponían

10 Recuérdese que Núñez escribe su primera relación en Cuba (1527). En Nueva España, él y sus compañeros redactarán otra para las autoridades virreinales, de la que hoy sólo se conserva un fragmento en la Colección de documentos inéditos relativos al descubrimiento, conquista y organización de las antiguas posesiones españolas en América y Oceanía. Ed. Luis Torres Mendoza (Archivo de Indias) (Madrid: Imprenta de José María Pérez, 1864-1884), pp. 265-269. Camino de España, Núñez, Castillo y Dorantes enviaron una más extensa a la audiencia de la Española que Fernández de Oviedo reprodujo parcialmente en su Historia general de Indias, IV, op. cit., pp. 285-318. En España se publicará la primera edición muy ampliada de la Relación que dio Alvar Núñez Cabeza de Vaca de lo acaecido en las Indias en la armada donde yua por gobernador Pánphilo de Narbáez, desde el año de veynte y siete hasta el año de treynta y seys que boluió a Sevilla con tres de su compañía (1542). Con numerosas revisiones Cabeza de Vaca publicó ese texto y sus Comentarios en Valladolid (1555). Para un estudio detallado de la evolución textual de los Naujragios, consúltese mi estudio preliminar a la primera edición crítica que en breve publicará Editorial Castalia. En este estudio cito por la edición M. Serrano y Sanz, Naufragios y Comentarios (Madrid: Colección de documentos inéditos para la historia de América, Librería general de Victoriano Strárez, 1906).

11 Se ha especulado sobre las razones que motivaron las narraciones de Alvar Núñez. No es ocioso hacerlo, pero recordemos, ante todo, que al salir de España él recibió instrucciones reales muy concretas - como era habitual entonces- que le obligaban a informar. Ese precioso documento aparece en la ya citada Colección de documentos inéditos, pp. 265-266. Los supervivientes de la expedición fueron: Alonso del Castillo Maldonado, natural de Salamanca; Andrés Dorantes, natural de Béjar (Prov. de Salamanca); Alvar Núñez Cabeza de Vaca, residente en Jerez de la Frontera, y Estebanico, marroquí, natural de Azamor (Cap. XXXVIII). La expedición de Narváez salió de Sanlúcar de Barrameda el 17 de junio de 1527. Los supervivientes llegaron andando a Nueva España en 1536. 
situadas al norte de Nueva España. Con esos objetivos, salieron fray Marcos de Niza y Vázquez de Coronado en sendas expediciones que a la larga regresarían con más noticias y ficciones que botín ${ }^{12}$. De lo que no cabe duda es que las noticias que produjo Cabeza de Vaca desataron aquel nuevo ciclo expedicionario que tanto ilusionó al virrey don Antonio de Mendoza ${ }^{13}$. Es razonable suponer, por tanto, que la magnitud de esos acontecimientos debieron de reafirmar en la mente de Alvar Núñez la importancia de los conocimientos que él poseía ${ }^{14}$.

De cara a sus objetivos inmediatos, la expedición de Pánfilo de Narváez a la Florida había sido un rotundo fracaso, pero con el paso de los años Alvar Núñez astutamente logró caracterizar la desastrosa aventura como lección provechosa de la que se obtuvo una importante recopilación informativa sobre áreas inmensas de Norteamérica de las que nada o poco se sabía.

«No me quedó ---dice Cabeza de Vaca en su cuidadoso proemiolugar para hacer más servicio deste, que es traer a Vuestra Magestad relación de lo que en diez años que por muchas y muy extrañas tierras que anduue perdido y en cueros, pudiese saber y ver, ansí en el sitio de las tierras y provincias y distancias dellas como mantenimientos... y todas las particularidades que pude alcançar y conocer... el cuydado y diligencia siempre fue muy grande de tener particular memoria de todo... Como la relación dello es auiso, a mi parecer no liuiano, para los que en su nombre fueren a conquistar aquellas tierras [sic] ${ }^{15}$.

Y aún con mayor suspicacia, Núñez reconocerá en varias porciones de sus Naufragios otras posibilidades no menos importantes que contienen sus escritos. Entre ellas señalará la propagación de la fe que debía llevarse a cabo y que él, en unión de sus compañeros, inició entre las tribus que entonces habitaban las inmensas zonas occidentales de Nueva España (cap. XXXVI) ${ }^{16}$. De hecho, al examinar las implicaciones de esa larga gestión evangelizadora identificaremos en ella una velada codificación de acciones ritualizadas que remiten, principalmente, a un

12 Sobre esos hechos e invenciones, véase la admirable obra de Luis Weckman La herencia medieval de México, 2 vols. (México: Colegio de México, 1984), pp. 58-62.

13 Interesa en este contexto la carta que Mendoza escribió sobre Cabeza de Vaca a la emperatriz. Colección de documentos inéditos..., Vol. XIII (Madrid: Imp. de J. M. Pérez, 1870), pp. 235-236.

14 Bishop, p. 170.

15 El subrayado es mío.

16 Gestión que se hace cada vez más evidente en Caps. XXV-XXXVI. 
copioso discurso hagiográfico y a creencias que tuvieron un profundo arraigo popular a lo largo de la Edad Media y aún después; fueron esas devociones y rituales las que los canonistas y teólogos escolásticos combatieron abiertamente desde el siglo xIII mediante nuevas exégesis doctrinales ${ }^{17}$. Las difundidas tradiciones populares de santos milagreros y errantes, en España y otras partes de Europa, las ha comentado Marcel Bataillon, pero han sido elucidadas con especial rigor en las actas y tratados preparados por los padres bolandistas ${ }^{18}$. Las que señalo ahora son tradiciones que figuraban de manera prominente en todo el trasunto de leyendas populares que sobresalen en la ficción medieval que también se propagó por el Nuevo Mundo ${ }^{19}$.

Pero al constatar estos hechos, entiéndase que no he querido inferir que Cabeza de Vaca haya articulado deliberadamente en sus Naufragios elementos concretos del código hagiográfico. Lo que pretendo demostrar, en las páginas que siguen, es que su texto como entidad escritural y transmisora recupera e integra componentes de esa tradición hagiográfica y legendaria; tradición convocada en estas instancias por un registro de asociaciones que son culturalmente inherentes al peregrinaje que Alvar Núñez nos describe. La manera en que él relata el tercio final de su trayectoria no podía menos que ser vinculada al vasto corpus de narra-

17 Los antecedentes y derivaciones de ese proceso en el Nuevo Mundo los expone Silvio Zavala en La filosofía politica en la conquista de América (México: Colegio de México, 1947), pp. 50-93. Interesa destacar que en esos debates doctrinales se aludía a la permanencia de creencias y tradiciones paganas en la hagiografía medieval. Una exposición más generalizada de esos hechos se encuentran en las siguientes obras: Alexander Murray, Religion and Society in the Middle Ages (Oxford: The Clarendon Press, 1978), pp. 20-55; Karl Rahner, "The Church of the Saints», en Theological Investigations, Vol. 3 (Baltimore: Helicon, 1967), y más concretamente Lawrence S. Cunningham, The Meaning of Saints (New York: Harper and Row, 1980), pp. 7-33.

18 Erasmo en España (México: Fondo de Cultura Económica, 1950), pp. 290, 570 y 735 . La obra más valiosa sobre la tradición hagiográfica se debe al eminente bolandista Père Hippolyte Delehaye, S. J., The Legends of Saints, trad. Richard J. Schoech (South Bend Indiana: Notre Dame University Press, 1961), pp. 148, 186-207.

19 Véase Jacques Lafaye, Quetzalcoatl y Guadalupe. La formación de la conciencia nacional en México. Prólogo de Octavio Paz (México: Fondo de Cultura, 1977), pp. 347-405. Sobre el dilatado alcance del folklore hagiográfico debe consultarse la importante obra de Peter R. L. Brown The Cult of Saints; its Rise and Function in Latin Christianity (Chicago: Chicago University Press, 1981). Agradezco a mi erudito colega Fernando Segovia - catedrático en la Escuela de Teología de Vanderbilt University - las valiosas pistas relacionadas con esta investigación. 
ciones centradas en el bregar de peregrinos, ermitaños y santos itinerantes que con tanta facilidad evocó la imaginación popular y culta del Medievo y el Renacimiento ${ }^{20}$. Es ese mismo legado el que se propaga: por el Nuevo Mundo para derivar en «la evangelización conquistadora» que patrocinaron los franciscanos y que tenía su raíz en las abstrusas doctrinas medievales de «las guerras justas» ${ }^{21}$. Es más: refiriéndose al Nuevo Mundo, Mendieta, entre otros, habla de los «caballeros de Cristo que venían a conquistar»; y en palabras de Luis Weckman, «todavía en 1629 los franciscanos de Nuevo México - -según lo dice la Segunda relación de la grandiosa conversión de aquel reino- eran 'soldados evangélicos' que con el arnés de la oración se armaban para sujetar y vencer engaños de Lucifer» ${ }^{22}$.

No olvidemos, en todo caso, que Alvar Núñez inicia su trayectoria americana en la época en que la Corona aún apoyaba diligentemente la evangelización fervorosa, de sesgo primitivo, como parte fundamental del proyecto conquistador ${ }^{23}$. Es precisamente en esas etapas iniciales cuando se gestan numerosas leyendas sobre las apariciones de santos. y las prédicas de apóstoles en el Nuevo Mundo ${ }^{24}$. Si tomamos en consideración ese amplio contexto de leyendas hagiográficas, no tiene por qué sorprendernos que elementos de esa tradición se insertarán en las se-

20 Sobre las conceptualizaciones medievales de la peregrinación, véase Delehaye, p. 186; Juan Eduardo Cirlot, Diccionario de Símbolos (Barcelona: Editorial Lobos, 1982), pp. 357-358. Sugestiva en este contexto es la edición y estudio preparado por José J. Arrom sobre José de Acosta, Peregrinación de Bartolomé Lorenzo (Lima: Petro-Perú, 1982).

21 Véanse Weckman, p. 226; Lafaye, Quetzalcoatl, pp. 205-289; Lewis Hanke, «Dawn of Conscience in America; the Spanish Experiments and Experiences with Indians in the New World», en Proceedings of the American Philosophical Society, Vol. XXXVIII, núm. 2 (1963), pp. 83-92.

${ }^{22}$ La herencia, I, p. 227. Las distinciones generales entre conquista y evangelización a veces eran tenues, sobre todo en los primeros treinta años de la colonización.

${ }^{23}$ Para una documentación analítica de ese contexto, véase John E. Elliott, El Viejo y el Nuevo Mundo (Madrid: Alianza Editorial, 1970), pp. 41-71.

24 Lafaye, Quetzalcoatl, pp. 219-253. Sobre todo las referencias a las imaginadas predicaciones de Santo Tomás en el Nuevo Mundo. Para datos aún más circunscritos a ese legado, consúltense los siguiente estudios: D. A. Brading, Prophecy and Myth in Mexican History. Cambridge Latin American Miniatures (Cambridge: Centre of Latin American Studies, 1984), pp. 3-31, y Beatriz Sune Blanco, «Religiosidad popular en Andalucía y América» (siglo xvII), en Andalucía y América en el siglo XVII (Sevilla: Escuela de Estudios Hispanoamericanos, C.S.I.C., 1984), pp. 163-185. 
cuencias episódicas de los Naufragios. Además, según lo veremos más adelante, esos eran recursos expositivos y argumentales que en más de un sentido se avenían con la proyección que Cabeza de Vaca quiso darle - por otras razones - a su narración. Sin rebuscar datos, puede comprobarse que, en los últimos capítulos de los Naufragios, Cabeza de Vaca y sus acompañantes van transformando el lento regreso a Nueva España en una creciente empresa evangelizadora que abarca tanto la prédica como las alusiones ocasionales a curas milagrosas. En su base, es la afirmación de un cristianismo cifrado en las obras de fe y en el que la acción contemplada en la especificidad de sus méritos llega a sustituir a todo intento de conceptualización doctrinal ${ }^{25}$. Es una tendencia que ya se manifiesta con toda claridad en el capítulo XXII. "Y como por toda la tierra no se hablasse sino de los misterios que Dios nuestro Señor con nosotros obraua, venían de muchas partes a buscarnos para que los curássemos, y al cabo de dos días que allí llegaron vinieron a nosotros vnos indios de los susolas e rogaron a Castillo que fuese a curar un herido... ${ }^{26}$.

Hay, inclusive, otros pasajes en los que la actividad evangelizadora aparece consumada, más en la prédica que en la acción milagrosa. Véamoslo:

Por todas estas tierras los que tenían guerras con los otros se hazían luego amigos para venirnos a rescibir y traernos todo cuanto tenían, y de esta manera dexamos toda la tierra en paz. Y dixímosles por las señas porque nos entendían que en el cielo auía un hombre que llamáuamos Dios, el qual aúa criado el cielo y la tierra, y que éste adoráuamos nosotros y teníamos por Señor y que hazíamos lo que nos mandaua y que de su mano venían todas las cosas buenas, y que si ansí ellos lo hiziessen les yría muy bien dello. Y tan grande aparejo hallamos en ellos que si lengua ouiera con que perfectamente nos entendiéramos todos los dexáramos christianos» (Cap. XXXI) ${ }^{27}$.

25 En buena proporción es la ausencia de ese discurso doctrinal to que aligera el proceso narrativo y da un sentido quizá más moderno al contenido testimonial de los Naufragios.

${ }^{26}$ Cabeza de Vaca no pierde oportunidad que le permita constatar la entereza de su fe, y de ella habla con la objetividad con que se describen otras cosas: «De mí sé decir que siempre tuue esperança en su misericordia que me había de sacar de aquella captiuidad, y así yo lo hablé siempre a mis compañeros» (capítulo XXIII).

${ }^{27}$ El subrayado es mío. 
Después de esta breve inspección de algunos fragmentos principales, tal vez no nos parecerán descabelladas las caracterizaciones que tantos han propuesto de Cabeza de Vaca como 'santo de la conquista'. Ya en el siglo xvıI el apasionado marqués de Sorito describía a Núñez como «una Teresa de Jesús» o como un "San Ramón Nonato», e inclusive le asocia con Xavier, "Apóstol de las Indias» ${ }^{28}$. Otros, con más fervor que datos, «lo destacan como figura serena... inconfundible con otra luz distinta... ${ }^{29}$. Se recordará, además, que varios expedicionarios que años después recorrieron parte de la ruta de Cabeza de Vaca, descubrieron que los indios de aquellas regiones lo recordaban con obvia veneración ${ }^{30}$. Pero no basta con verificar esa imagen que desde el siglo xvI se creó en torno a la persona de Alvar Núñez. Lo que me parece necesario al considerar estos datos es que identifiquemos, con alguna especificidad, los componentes de los Naufragios que favorecieron ese género de apreciaciones.

En la narración de Cabeza de Vaca, la catástrofe final, que se produce con la dispersión de las embarcaciones ${ }^{31}$ y sus sucesivos naufragios, conduce a estadíos de aislamiento por parte de los supervivientes, aislamiento que se hace singularmente notorio en la persona de Cabeza de Vaca: «Fueron casi seis años - nos dice él- el tiempo que yo estuue en esta tierra solo entre ellos y desnudo...» (Cap. XVI). Tradicionalmente en esa etapa subsiguiente al naufragio (en su acepción literal y metafórica) ${ }^{32}$ suelen enunciarse reflexiones iluminadas que emite la persona que ha sufrido el desastre. Es notable, sobre todo, una tendencia a la introspección que suele limpiar los ojos del que ha padecido ofus-

${ }^{28}$ En la nota 8 se han señalado las obras en que repetidamente se ofrecen esas descripciones de Núñez.

29 Carlos Zubizarreta, Capitanes de la aventura: Cabeza de Vaca el infortunado (Madrid: Instituto de Cultura Hispánica, 1975). No así Serrano y Sanz; en el estudio preliminar de su edición se burla de Núñez. Para nuestra sorpresa, el erudito le achaca «no tener espíritu de observación»; y añade que «quizá sea cierto que su imaginación de andaluz amplificase los detalles». Además, Serrano califica la apología de Ardoíno «como escrito farragoso» - que lo es- y al mismo tiempo - con fervor polémico- acusa a Cabeza de Vaca de «puras invenciones», pp. vii-ix.

30 Weckman, I, op. cit., p. 338.

31 Cap. XVII. Es sugestiva, en el contexto de este trabajo, la alusión que hace Bachelard al sentido tradicional de la «barca» -que los supervivientes desesperados construyen en los Naufragios - como la «cuna recuperada». Citado por Cirlot, op. cit., p. 98.

32 Sobre el contenido metafórico, véase Luisa Pranzetti, op. cit., pp. 15-28. 
caciones previas que acaso le llevaron a la via non vera. Es así, por ejemplo, como lo manifiesta San Agustín precisamente ante el impacto del naufragio; particularmente en el sufrido por Ulises ${ }^{33}$. El viaje, y su descalabrado fin, determina una evaluación de las experiencias que han hecho posible esa desastrosa conclusión. En su sentido metafórico, Dante, en otro contexto, alude a esa misma necesidad como lúcidamente lo ha demostrado John Freccero. En el Convivio se indican las vías de superación que deben suceder al naufragio espiritual; además se señalan cuáles deben ser los esfuerzos que nos permitirán alcanzar virtude e conoscenza ${ }^{34}$; esfuerzos que idóneamente deben conducirnos a una comprensión más satisfactoria y atinada de nuestras posibilidades objetivas y condición espiritual.

En ese proceso de reconsideraciones ha de cumplirse, como etapa previa, una severa reducción de posibilidades que vuelca la conciencia del protagonista sobre su estado de crisis. Desprovisto de opciones alentadoras, y ante «la noche oscura» que augura una muerte tras otra, Alvar Núñez, en su penosa vigilia, confesará con un latiguillo oximorónico: "Yo cierto aquella hora de muy mejor tuoluntad tomara la muerte, que no ver tanta gente delante de mí de tal manera. $Y$ después que el maestre tomó cargo de la barca, yo reposé vn poco muy sin reposo, ni auía cosa más lejos de mí entonces que el sueño» (Cap. X). Pero en ese trance desesperado, Núñez gradualmente transformará su endeblez y desventuras en fortaleza para hacerse guía de los que desfallecen. Su descripción, en estas páginas, adquiere un rico sentido figurativo que se ha confirmado en estudios anteriores ${ }^{35}$.

33 Véase D. Thompson, «Dante's Prologue Scene», Dante Studies, LXXXIV (1967), pp. 1-33, 58. Las ricas connotaciones del naufragio en la Antiguiedad y el Medievo las expone John Freccero en su brillante estudio «Dante's Prologue Scene», Dante Studies, LXXXIV (1966), pp. 1-27.

${ }^{34}$ Las implicaciones que discute Freccero se confirman en La tempestad, de William Shakespeare. Véase también el excelente estudio preliminar que en su edición de esa obra ofrece Frank Kermode, The Tempest (London: Methuen \& Co. Ltd., 1966), pp. XXIV-XLIII.

35 Interesan, en el marco de esta lectura, las repetidas alusiones que se hacen en los Naufragios a la «noche oscura» (Caps. I, IX, X, XVI). En su simbolismo tradicional - relacionado especialmente con la navegación-, «las tinieblas, la noche y la selva oscura" infieren la presencia de potencias no desarrolladas y la proximidad al caos. Para ilustraciones literarias de ese trasunto, véase Richard H. Lansing, «Two Similes in Dante's Commedia: The Shipwrecked Swimmer and Elijah's Ascent», en Romance Philology, XXVIII, núm. 2 (1974), pp. 162-163. 
$Y$ quanto vino la noche no quedamos sino el maestre e yo que pudiéssemos marear la varca; y a dos horas de la noche el maestre me dixo que yo tuuiesse cargo della, porque él estaua tal que creya aquella noche morir. $Y$ assí yo tomé el leme y pasada media noche, yo llegué por ver si era muerto el maestre, y él me respondió que él antes estaua meior y que él gouernaría hasta el día (Cap. X) ${ }^{36}$.

Paralelamente a esa recuperación que nos revela este párrafo, en los Naufragios destaca un proceso graduado de superación del caos primitivo ${ }^{37}$ que ha supuesto la regresión ineludible a formas paganas de vida ${ }^{38}$ que sufren Cabeza de Vaca y sus acompañantes (Caps. VII-XVI). Sin proponer aquí el tradicional esquema alegórico y dantesco que presupone la 'perdición' y las acciones de fe que a la postre la redimen, Núñez protagoniza, a su manera, «un regreso» no sólo a España como entidad geográfica, sino más bien el retorno a un orden de vida que sin su liderazgo hubiese sido imposible ${ }^{39}$. Al relatar su larga y penosa estadía en aquellas costas agrestes, Núñez nos aclara que: «La razón por que tanto me detuue fue por llevar conmigo un cristiano que estaua en la isla (del Mal Hado) llamado Lope de Oviedo» (Cap. XVI). En otros fragmentos se hará aún más visible esa labor de rescate que Cabeza de Vaca inicia; labor que también implica un nivel de protagonismo narrativo que se consolida visiblemente en la proyección autobiográfica de la narración ${ }^{40}$.

${ }^{36}$ El subrayado es mío.

37 Véase Molloy, op. cit., p. 763.

38 Sobre el concepto del retorno al paganismo como expresión óptima del caos, véase Ernest Curtius, European Literature and the Latin Middle Ages, trad. Willard R. Trask (Princeton: Princeton University Press, 1973), pp. 111-112.

39 Ese retorno es también calificado como inversión histórica, pero sobre todo espiritual. Consúltese Cirlot, op. cit., p. 168. Sobre otros tópicos que aluden a la inversión de valores, véase Curtius, ibid., pp. 94-98.

40 Aunque indudablemente se trata de meras coincidencias, observaremos, en términos de sus referentes culturales, que el cruce de "ríos» y «ancones» y el paso a las zonas desérticas, evoca el passo a otro estado, sobre todo, en el contexto bíblico de éxodo, pero también en el literario, si se piensa, sobre todo, en pasajes de la Divina Comedia -(Inferno, 1:22) -, en los que Dante, peregrino y náufrago, emprende alegóricamente otra ruta y también otra etapa en su evolución espiritual. Véase John Freccero, "The River of Death: Inferno II, 108», en The World of Dante: Six Studies in Language and Thought, Ed. S. B. Chandler y J. A. Molinaro (Toronto: University of Toronto Press, 1966), p. 26. Sobre la dimensión instructiva del viaje, véanse Angel Delgado, «El viaje como medio de conocimiento», Actas del VIII Congreso Internacional de Hispanistas (1984), pp. 1-11, y Christian K. Zacher, Curiosity and Pilgrimage (Baltimore: Johns Hopkins University Press, 1976), pp. 88-92. 
Dimos muchas gracias a Dios de vernos juntos, y este día fue uno de los de mayor plazer que en nuestros días auemos tenido. Y llegado donde Castillo estaua me preguntaron que donde yo yua. Yo le dije que mi propósito era de passar a tierra de christianos y que en este rastro y busca yua. Andrés Dorantes respondió que muchos días hauía que él rogaua a Castillo y a Esteuanico que se fuesen adelante, y que no lo ossauan hazer porque no sabían nadar y que temían mucho los ríos y ancones por donde auían de passar, que en aquella tierra ay muchos. Y pues Dios nuestro Señor auía sido seruido de guardarme entre tantos trabajos y enfermedades y al cabo traerme en su compañía, que ellos determinatian de huyr, que yo los passaría de los ríos y ancones que topássemos... (Cap. XVII) ${ }^{41}$.

Dentro del marco de apreciaciones que he desarrollado hasta aquí, es significativo ese desplazamiento hacia circunstancias más civilizadas; y sobre todo hacia un progresivo estado de gracia en el que la misericordia divina se hace cada vez más patente. Pero también es evidente que esas retribuciones de la voluntad divina han sido precedidas por estadios de cautiverio, castigos, humillaciones y «por la separación». Son experiencias que de inmediato asociamos con los martirios y las soledades que preceden a la beatitud. El aislamiento en zonas desérticas evoca famosos episodios bíblicos, pero sobre todo la penuria ascética de santos y ermitaños que, en imitación de Cristo, ansiaban las gratificaciones de una espiritualidad depurada de intereses mundanos. Tal es la percepción e imagen que la tradición hagiográfica ha difundido, en versiones disímiles, acerca de Josafat ${ }^{42}$, Luciano y Clemente entre muchos otros santos históricos y legendarios que se remontan a los albores de la cristiandad ${ }^{43}$. Elementos de esa rica tradición narrativa se evocan en pasajes de los Naufragios que versan sobre la estadía de Cabeza de Vaca en zonas semidesérticas que hoy configuran el sur de Texas y

41 En relación a esos estadíos de pruebas arduas véase el análisis que Hippolyte Delehaye ofrece, por ejemplo, de la leyenda hagiográfica de San Procopio, op. cit., pp. 130-133 y 193.

42 Dada la compleja evolución de la leyenda de Baarlam y Josafat y de los manuscritos conocidos hasta hoy, es preciso aclarar que me refiero a las versiones portuguesas (siglo xIV) y sobre todo a las españolas editadas por John E. Keller, Robert W. Linker, Baarlam e Josafat (Madrid: C.S.I.C., 1979). Por su parte, Delehaye ha estudiado cómo las tradiciones populares dramatizan ese anecdotario imaginativo relacionado con las facultades sobrenaturales de santos. De especial interés, entre otras, es la leyenda valenciana de Santa María del Grao, op. cit., pp. 30-31.

${ }^{43}$ En relación con los temas que se tratan en estos apuntes, es de especial interés la asociación que en el Cap. XVIII casualmente hace Cabeza de Vaca: «y cuando parten (los indios), tales van de los mosquitos que paresce que tienen enfermedad de San Lázaro». 
Nuevo México: «y la tierra es tan áspera y tan cerrada que muchas veces hazíamos leña en montes, que quando la acabáuamos de sacar nos corría por muchas partes sangre de las espinas y matas con que topáuamos...» (Cap. XXII) ${ }^{44}$.

Encauzada así nuestra lectura, se percibirá que, sobre todo en la segunda mitad de los Naufragios, se insinúan acciones y hechos que tienen una clara procedencia ritualizada en la tradición hagiográfica. Son especialmente sugestivas las repetidas alusiones que en el texto se hacen a la desnudez, como estadío simbólico representativo de una mutación primordial en status, pero que conlleva un ánimo de renuncia indispensable en todo proceso de renovación espiritual. En los Naufragios la desnudez ciertamente alude a una drástica reducción de status y es, al mismo tiempo, como nuditas virtualis, el estadío que favorece reflexiones más sobrias y penetrantes sobre nuestra índole originaria. Los precedentes de esa fase que conocemos en la hagiografía son célebres y han alcanzado una gran difusión. La desnudez de San Bernardo (1091-1153) ${ }^{45}$ es legendaria, pero no menos sufrida que la que se impuso San Brendano en el siglo XII ${ }^{46}$; también nos es fácil recordar que ecos de ese

44 Ese tipo de reflexión destaca en seguida y en los Naufragios tiene un carácter excepcional, porque aparece con una curiosa alusión oximorónica a la 'fortuna' como estado calamitoso: «Los indios, de ver el desastre que nos auía venido y el desastre en que estáuamos con tanta desuentura y miseria, se sentaron entre nosotros y con el gran dolor y lástima que ouieron de vernos en tanta fortuna (así se lee en las ediciones de 1542 y 1555) començaron todos a llorar rezio y tan de verdad que lexos de allí se podía oyr, y esto les duró más de media hora, y cierto, ver que estos hombres tan sin razón y tan crudos, a manera de brutos, se dolian tanto de nosotros que en mí y en otros de la compañía cresciesse más la passión y la consideración de nuestra desdicha...» (Cap. XII). El subrayado es mío.

45 Las leyendas hagiográficas que versan sobre San Bernardo se ofuscan debido a las confusiones que se crean entre Bernardo de Chartres (ca. 1136), Bernardo Silvestris (ca. 1150), Bernardo de Clairvaux y el Bernardo Cluníaco de Morlaix, autor de la famosa De contemptu mundi; es a este último a quien, en su desgarrado ascetismo se atribuyen prolongados retiros en la desnudez. Sobre el alcance de sus textos, véanse Curtius, op. cit., p. 122, y M. Bataillon, op. cit., p. 290.

46 De la Navigatio Sancti Brendani Abbatis tomo el siguiente fragmento: «Erat enim coopertus totus capillis suis et barba et ceteris pilis usque ad pedes, et erant candini sicut nix pre nimia senectute. Tantum facies et oculi uidebantur illus. Nihil aliud indumenti erat sibi iunctum exceptis pilis qui egrediebantur de suo corpore. At uero sanctus Brendanus, cum hec uidissett... Ciertamente estaba cubierto por el pelo de su barba hasta los pies y eran cabellos blancos debido a su avanzada edad. Sólo su cara y ojos podían distinguirse. No vestía ropa alguna, sólo le cu- 
desgarrado ascetismo que se traduce en dilatadas penitencias reaparecerá en el Amadís de Gaula (1365?) en su guisa de Beltenebros y ciertamente en el Quijote ${ }^{47}$. También semidesnudo y amparado por sus largos cabellos y barbas - como los santos medievales- estaba Alvar Núñez al llegar a Nueva España ${ }^{48}$. Los ecos de la desnudez ascética aparecen múchos antes en sus Naufragios; a ella se refiere dos veces en su proemio, pero con mayor expresividad será descrita en varios fragmentos de la narración. Núñez se describirá, por ejemplo, extraviado en aquellas planicies desérticas padeciendo la soledad y las más crudas penurias.

Y como por toda esta tierra no ay caminos yo me detuue más en buscarla, la gente se boluió e yo quedé solo, y veniendo a buscarlos aquella noche me perdí y plugo a Dios que hallé vn árbol ardiendo y al fuego del passé aquel frío aquella noche, y a la mañana yo me cargué de leña y tomé dos tizones y boluí a buscarlos y anduue desta manera cinco días, siempre con mi lumbre y carga de leña, porque si el fuego se me matasse, en parte donde no tuuiese leña, como en muchas partes no la aúa, tuuiesse de que hazer otros tizones y no me quedasse sin lumbre, porque para el frío yo no tenía otro remedio... (Cap. XXI) ${ }^{49}$.

brían los cabellos que de su cuerpo nacían. Y así según se ha dicho estaba San Brendano», Ed. de Carl Selmer (South Bend Indiana: Notre Dame University Press, 1959), p. 72. Otros pasajes igualmente reveladores como ejemplo de la desnudez ascética en el Medievo aparecen en The Anglo-Norman Voyage of St. Brendan, Ed. E. G. R. Waters (Oxford: Clarendon Press, 1928), pp. 79-81. Episodios similares se evocan también en pasajes de $A$ Santa María Egipcíaca, en la versión de Francisco de Sa e Miranda (siglo xvI): Descalça e despida andou / despresando a gloria falsa / com que o mundo a enganou / e por despida e descalsa / Deus d'ella se affeicoou. / Dos cabellos so se fuesa / nao pela belleza d'elles / que ya nao tinha belleza, / mas por se cobrir com elles / elh'os das a natureza (Porto: Livraria Chardon, 1913), p. 87. El contexto episódico es de origen griego. Otras versiones se conocen, por ejemplo, en La leyenda áurea de Jacobo de Vorágine, que a su vez difiere en pasajes descriptivos de las italianas y francesas. Al parecer, la versión inglesa, muy próxima a la reproducida aquí, aparece en la edición de M. Cook, Saint Mary the Egyptian (London: J. R. Smith, 1852). Obra esta que no he podido consultar.

47 Otras alusiones se hacen a ese mismo motivo y sus antecedentes literarios en el Cap. XXV del Quijote, Ed. de Martín de Riquer (Barcelona: Editorial Juventud, 1970).

48 Véanse Cap. XXXIII y Weckman, op. cit., p. 160.

49 Otros testimonios evocan aún con mayor crudeza sus estrecheces: «Con estos padescimos más hambre que con los otros, porque en todo el día no comíamos más de dos puños de aquella fruta, la cual estaua verde; y con tener falta de agua, daba mucha sed a quien la comía; y como la hambre fuese tanta, nosotros comprámosles dos perros (tal vez coyotes) y a trueco dellos les dimos unas redes y otras cosas y un cuero con que yo me cubria» (Cap. XXII). El subrayado es mío. 
Las ya legendarias andanzas de Cabeza de Vaca por las áreas semidesérticas del oeste norteamericano llegan a transmutarse en una construcción narrativa que paulatinamente se convierte en una suerte de peregrinación, cuyos hitos principales —más aún que los geográficosserán las curas milagrosas, las instancias de misericordia divina (capítulos XIII, XIV, XIX) y la propagación de la fe mediante prédicas y testimonios (Caps. XXX-XXXVI). Reconoceremos en seguida que ese peregrinaje milagroso y colectivo nos remite a una tradición hagiográfica de fértil raíz popular en la que se glorifican santos y mártires errantes que se asociaron sobre todo con las prédicas legendarias de los apóstoles y luego con órdenes medicantes ${ }^{50}$. En las utopías populares del Medievo, esos santos itinerantes a menudo eran seguidos por fieles y comunidades que intentaban apropiarse de ellos y de la bienaventuranza representada en sus acciones y persona ${ }^{51}$. En ese vagar de figuras santificadas por aureolas de creencias populares, la perpetración de milagros y la identificación de reliquias serían actividades muy señaladas a lo largo del Medievo ${ }^{52}$. De tales incidentes derivó un acervo inagotable de leyendas que difundieron -en versiones dispares - la tradición oral, manuales de predicación y noticias transmitidas en guisas juglarescas ${ }^{53}$. Ese copioso material legendario cifrado en apariciones, profecías y milagros eran componentes nucleares de innumerables narraciones populares ${ }^{54}$; eran relatos en los que el milagro casi se convierte en un programa de acción que a la postre deriva en concepciones de la santidad heroica; concepción esa que tan notable arraigo tuvo en España, el Nuevo Mundo, así como en la historiografía y la ficción ${ }^{55}$.

En el mundo hispánico, las conocidas aventuras del apóstol Santiago ofrecen el ejemplo más difundido de esa tradición legendaria que exalta

50 Véase Bataillon, op. cit., p. 290.

51. Ejemplos de esa apropiación las describe H. Delehaye al referirse al heró́smo de los santos. Op. cit., p. 87.

52 Bataillon, op. cit., p. 570.

53 Delehaye ha puesto de relieve las múttiples convergencias que se producen desde principios del Medievo entre la hagiografía y la tradición literaria, dando lugar - como antes lo he señalado- a una vasta intromisión de motivos paganos. Op. cit., pp. 51 y 109.

.54 «El cuento del ermitaño de Valencia», recogido por Alfonso Martínez de Toledo, arcipreste de Talavera (1398-1470), es un ejemplo atractivo de esas formas de transmisión. Cuentos viejos de la vieja España, Ed. C. Sainz de Robles (Madrid: Aguilar, 1964), p. 260. El conocido «Doble milagro» de Mateo Alemán es otro ejemplo interesante que también se recoge en este mismo libro, p. 771.

55 Véase Delehaye, op. cit., pp. 140-141, 145, 114, 119, 160. 
la santidad heroica ${ }^{56}$. Pero mayoritariamente las acciones milagrosas documentan curaciones espectaculares y otras revelaciones de poderes sobrenaturales que en algunos casos derivan en anécdotas singularizadas por su trivialidad ${ }^{57}$. Con todo, las resucitaciones proveían en la Edad Media las instancias más imponentes de facultades milagrosas. Son casi innumerables los incidentes que podrían enumerarse y que se recogen en la ya afamada Biblioteca hagiográfica latina ${ }^{58}$. Creo que a ese legado de prodigios pertenece el más célebre episodio de los Naufragios en el: que Alvar Núñez revive a un indio que ya todos daban por muerto. Es un episodio notable que de inmediato evoca -entre otros - los milagros de índole similar que G. Huffer, Conrad y L. Herbert le atribuyen a San Bernardo ${ }^{59}$. Por su obvia importancia reproduzco, en su totalidad, el incidente narrado por Núñez.

Los indios me dixeron que yo fuesse a curarlos, porque ellos me querían bien e se acordauan que les auía curado en la nuezes e por aquello nos auían dado nuezes e cueros, y esto auía passado quando yo vine a juntarme con los christianos, e assí huue de yr con ellos y fueron conmigo Dorantes y Estetanico. Y cuando llegué cerca de los ranchos que ellos tenían yo vi el enfermo que ýuamos a curar, que estaua muerto, porque estaua mucha gente al derredor del llorando, y su casa desecha, que es señal que el dueño estaua muerto. $Y$ ansí, quando yo llegué hallé el indio los ojos bueltos e sin ningún pulso e un todas señales de muerto, según a mí me paresció, e lo mismo dixo Dorantes. Yo le quité vna estera que tenía encima, con que estaua cubierto, y lo mejor que pude supliqué a nuestro Señor fuesse servido de dar salud a aquel y a todos los otros que della tenían necessidad. Y después de santiguado y soplado muchas vezes me traxeron su arco y me lo dieron y una sera ${ }^{60}$ de tunas molidas, e lleuárome a curar otros muchos que estaban malos... Esto causó muy gran admiración y espanto y en toda la tierra no se hablaua de otra cosa (Cap. XXII).

56 Véase Inca Garcilaso de la Vega, Comentarios reales (II, II, Cap. XXIV). Ejemplos seminales de la santidad heroica personificada en San Teodoro y San Jorge las discute Delehaye, ibid., p. 110.

57 Véanse, entre otros, los comentarios de Delehaye sobre Santa Martina, Santa Bárbara y Santa Catalina, pp. 110-111.

${ }^{58} \mathrm{Un}$ análisis de esas fuentes -incluyendo la Analecta Bollandina- se resume en el estudio de David Knowles, «The Bollandists», The Transactions R. H. S., VIII, (1958), pp. 27-82.

59 Sobre lo que aportan esos autores, véase la nota 17.

60 Bolsa de forma rectangular, más ancha que larga, hecha generalmente de esparto, que se emplea para contener y transportar cosas. El derivado serón aún se utiliza en Cuba y otras regiones hispanoamericanas. María Moliner, Diccionario 
Como en las curaciones milagrosas atribuidas a santos y creyentes de la cristiandad medieval, las de Núñez se efectúan como acto que supera el trasunto mágico y diabólico que en los Naufragios representa Mala Cosa, personaje que practicaba curiosas incisiones en el tórax y abdomen de enfermos.

Estos [indios] y los de más atrás nos contaron vna cosa muy estraña, y por la cuenta que nos figuraron parescía que auía quinze o diez y seys años que auía acontescido, que dezían que por aquella tierra anduuo vn hombre que ellos 1laman mala cosa, y que era pequeño de cuerpo y que tenía baruas, aunque nunca claramente le pudieron ver el rostro y que cuando venía a la casa donde estauan se les leuantaban los cabellos y temblatian y luego parescía a la puerta de la casa vn tizón ardiendo e luego aquel hombre entraua y tomaua al que quería dellos e dáuales tres cuchilladas grandes por las hijadas con vn pedernal muy agudo, tan ancho como vna mano e dos palmos en luengo, y metía la mano por aquellas cuchilladas y sacáuales las tripas y que cortaua de una tripa poco más o menos de vn palmo y aquello que cortaua echaua en las brasas... y dezíannos que luego quedaban sanos, y que muchas vezes quando baylaua aparecía entre ellos, en hábito de muger vnas vezes y otras como hombre... que le preguntauan donde venía e a que parte tenía su casa, e que les mostró una hendeduras de la tierra e dixo que su casa era allá debaxo. Destas cosas que ellos nos dezían nosotros nos reyamos mucho, burlando de ellas, e como ellos vieron que no lo creymos, truxeron muchos de aquellos que dezían que él auía tomado y vimos las señales de las cuchilladas que él auía dado en los lugares, en la manera que ellos contauan. Nosotros les diximos que aquel era un malo y de la mejor manera que podimos le dáuamos a entender que si ellos creyessen en Dios nuestro Señor e fuessen christianos, como nosotros, no ternían miedo de aquel, ni osaría venir a hazelles aquellas cosas... (capítulo XXII) ${ }^{61}$.

del uso del español (Madrid: Edit. Gredos, 1970). Sobre este episodio afamado de los Naufragios, véase el agudo ensayo de David Lagmanovich, «Los Naufragios como construcción narrativa», Kentucky Romance Quarterly, XXV (1978), páginas 27-37.

61 El material sobre apariciones diabólicas en la historiografía de Indias es variadísimo y casi siempre denota procedencia medieval. Véase Luis Arocena, Antonio Solís, cronista indiano: Estudios sobre las formas historiográficas del barroco (Buenos Aires: E.U.D.E.B.A., 1963), pp. 9-60; y mi estudio «La historia como pretexto: formas de invención literaria en «El carnero», en La vocación literaria del pensamiento histórico en América (Madrid: Editorial Gredos, 1983), pp. 123-155. Valioso es el estudio de Sabino Solá, El diablo y lo diabólico en las letras americanas (Madrid: Editorial Castalia, 1973). 
Advertiremos, a propósito de estos y otros episodios similares, que el ritual empleado por Núñez y sus compañeros en esas curaciones remite con toda claridad a procedimientos que tradicionalmente se utilizaron en acciones milagrosas; son incidentes que la erudición hagiográfica e histórica ha puntualizado con toda precisión. Entre esos rituales a que recurre Cabeza de Vaca se distinguen: rezos (el padrenuestro, Cap. XV), soplos milagrosos (Cap. XII), santiguar el enfermo (Capítulo XV) ${ }^{62}$; además, en el contexto de estas referencias a un amplio sustrato hagiográfico y de rituales populares, interesa la preciosa noticia recogida por Luis Weckman sobre la espectacular llegada de Alvar Núñez a Nueva España, vestido con cueros de venados y con la piel y cabellos curtidos por años de vida a la intemperie.

Las fuentes históricas —señala Weckman - mencionan aquí y allá otros himnos medievales importados a la Nueva España. En 1537, según cuenta un acompañante de los Montejos (del Viejo y de su hermano Juan) en una incursión a las Hibueras, en la consagración de la iglesia de Comayagua (hoy en Honduras) se cantó el himno Vexilla regis prodeunt. Cuando un año antes Cabeza de Vaca y sus compañeros lograron retınirse con otros españoles en Sinaloa, después de interminables peripecias, expresaron su júbilo en este mismo canto. El himno Vexilla regis fue quizá compuesto en Poitiers en el siglo vII... a partir de 1569 se cantaba en la catedral de México ${ }^{63}$.

La información aportada por Weckman alude a un registro de ceremonias populares que figuraban de manera prominente en las creencias y el folklore hagiográfico que se difundió por el Nuevo Mundo. Entre los muchos ejemplos que podrían ilustrar la persistencia de ese patrimonio, figuran los esfuerzos e importantes inversiones que hizo la Corona para ubicar las míticas siete ciudades de Cébola; hechos de ese cariz nos indican, con toda especificidad, cuán tenue era la zona que existía entonces entre la creencia y las exigencias pragmáticas que imponían los programas de gobierno ${ }^{64}$. Larguísima es, por cierto, la lista de supuestos acontecimientos milagrosos que recogen cronistas laicos y religiosos en diversas partes del Nuevo Mundo ${ }^{65}$; en ese sentido son de interés los

62 Cirlot, op. cit., pp. 336, 420; Delehaye, p. 157; Bataillon, p. 735.

63 Weckman, op. cit., p. 316.

64 Ibid., pp. 49-59.

65 Véase Enrique Gandía, Historia crítica de los mitos de la conquista americana (Madrid: Sociedad General Española de Librerías, 1929), pp. 49-55; Antonio Antelo, «E1 mito de la Edad de Oro en las letras hispanoamericanas del siglo XvI», Thesaurus, XXVII (1973), pp. 279-330; Gonzalo Menéndez Pidal, Imagen del 
testimonios que recopilaron Dávila Padilla, Alonso Fernández y González Dávila entre otros ${ }^{66}$.

Los datos que he señalado y los fragmentos citados, ponen de relieve una sutil inversión retórica en los Naufragios, que hasta hoy no creo, que se haya consignado; es, además, una dimensión que no podemos ignorar al proponernos una caracterización objetiva del texto. Según lo he apuntado, las secuencias narrativas iniciadas en las constataciones forenses de los primeros siete capítulos evolucionan -expositivamentehacia una relación de sesgo autobiográfico; sección que culmina con los naufragios, la estancia en la fatídica isla del Mal Hado y los intentos de fuga (Cap. XX). Pero tras largos períodos de aislamiento y vejaciones sufridas por los cuatro supervivientes, la narración - sin abandonar su directriz autobiográfica - se transforma gradualmente en una breve crónica de peregrinaciones evangelizadoras y de milagros; proyección narrativa que, como ya se ha visto, se apoya en codificaciones reconocidas y en un ceremonial que se remonta al vasto sustrato hagiográfico del Medievo. Sin incidir en otras cuestiones, mi lectura de los Naufragios me lleva a concluir que esa inversión retórica emana de una estrategia sustitutiva.

Con ello quiero decir que, ante el desastre militar y económico que representó la expedición de Narváez, en los Naufragios —años despuésse sustituye gradualmente la narración conquistadora, de estirpe castren$\mathrm{se}^{67}$ por la otra y única posible vertiente positiva y heroica que aún admitía un discurso de esa índole; me refiero a la conquista evangelizadora, que como bien sabemos, estaba plenamente sancionada por el proyecto imperial que España desarrollaba en el Nuevo Mundo. Es esa opción la que por asociación inserta en el texto ecos de las codificaciones hagiográficas que de tantas maneras aún nutrían la imaginación popular y literaria. Pero, al subrayar la presencia de esa inversión retórica, no puede descontarse el efecto catalítico que tienen, en este contexto, las aspiraciones políticas y personales de Alvar Núñez. Si los leemos de cara a esas consideraciones, se observará que los últimos capítulos de los

mundo hacia 1570 (Madrid: Gráficas Ultra, 1944), pp. 26-33, y Antonello Gerbi, La disputa del Nuevo Mundo (México: Fondo de Cultura, 1960), pp. 7-44.

66 Weckman, op. cit., pp. 319-338-339.

67 De esa índole es la descripción que se ofrece de la construcción de barcas, así como las exploraciones que el mismo Alvar Núñez ordena (Caps. VI, VII). Nótese el cariz de la siguiente frase: «Otro día a la mañana yo les rompí más de treinta canoas...» (Cap. IX). 
Naufragios desarrollan, en su base, un nivel de argumentación política similar -aunque de menor vuelo- al que enunciaba Hernán Cortés en sus Cartas de Relación ${ }^{68}$.

Es indudable que Núñez quiere -a partir de su proemio- significarse como depositario de conocimientos excepcionales que le califican no sólo para retomar la empresa frustrada de Narváez, sino, además, para llevar a cabo la deseada conquista de las zonas occidentales de la Nueva España. Su conocimiento directo de la geografía, climas, pueblos y lenguas contenidas en aquellas regiones le proyectaban como la persona idónea para borrar aquel fracaso. En su persona se fundían el rango, ya conseguido, su probada superioridad física, facultad de liderazgo, fervor evangélico y una inquebrantable lealtad a la Corona. Todo ello se arguye implícitamente en los Naufragios. Si Cortés se presenta a sí mismo como la persona idealmente calificada para conquistar Nueva España, Cabeza de Vaca querrá ser otro tanto en las inhóspitas y primitivas regiones de Norteamérica. Desde sus disensiones iniciales con Narváez (Caps. IV, V, VII), Núñez subraya la sucesión de errores que marcaron la trayectoria de la expedición; más tarde, al aproximarse a la conclusión de su relato, Cabeza de Vaca no sólo indica los recibimientos triunfales que le tributaban los indios a él y a sus acompañantes, sino que también se refiere, con vehemencia, a los errores e ignorancia de tropas virreinales que pretendían esclavizar los indios: «y de allí en adelante - nos dice Núñez - vivieron con nosotros seis christianos [soldados a las órdenes de Melchor Díaz] que traían quinientos indios hechos esclavos» (capítulo XXXVI). Fue esa torpeza de las tropas españolas, según Cabeza de Vaca, lo que hizo que las comunidades indígenas se refugiaran en las sierras. Pero él también nos dirá que esas ineptitudes serían enmendadas gracias a su intervención.

Como los indios se boluieron todos, los de aquella prouincia (Nueva Galicia) que eran amigos de los christianos, como tuuieron noticia de nosotros nos vinieron a ver y nos truxeron cuentas y plumas. $Y$ nosotros les mandamos que hiziessen yglesias y pusiessen cruzes en ellas, porque hasta entonces no las auian hecho. Y hezimos traer los hijos de los principales señores para bautizarlos... Y después de baptizados los niños nos partimos para la villa de Sant Miguel, donde como fuymos 1legados vinieron indios que nos dijeron como mucha

68 Véase el excelente estudio de John E. Elliott «The Mental World of Hernán Cortés», Transactions of the Royal Historical Society, XVIII (1967), pp. 41-58. 
gente baxaua de las sierras y poblauan en lo llano y hazían yglesias y cruzes $y$ todo lo que le auiamos mandado... (Cap. XXXVI) ${ }^{69}$.

Más adelante, en ese mismo capítulo y con oportuna astucia, Núñez añadirá: «Dios nuestro Señor, por su infinita misericordia, quiera que en los días de Vuestra Majestad y debajo de uuestro poder y señorío, estas gentes vengan a ser verdaderamente y con entera voluntad sujetas al verdadero Señor que las crió y redimió. Lo cual tenemos por cierto que así será, y que Vuestra Majestad ha de ser el que lo ha de poner en efecto (que no será tan difícil de hacer)» ${ }^{70}$. Para consolidar las posibilidades que después del fracaso ahora le ofrecían sus triunfos personales, Núñez regresará a Castilla en vez de permanecer en Nueva España y aceptar - como lo hicieron sus acompañantes- las tentadoras ofertas colonizadoras y burocráticas que le hacían las autoridades virreinales. Aunque hoy nos parezca increíble, el objetivo de Cabeza de Vaca era retornar como gobernador a la Florida, pero descubrirá, al llegar a España, que esa prerrogativa que él creía merecer, por encima de todos, ya se la había otorgado la Corona a Hernando de Soto ${ }^{71}$. Una vez reconocidas las aspiraciones y estrategias que entonces desvelaban a Cabeza de Vaca, comprenderemos que él debió de ver sus Naufragios como la más persuasiva argumentación que le era posible ofrecer para lograr reconocimientos y cargos de genuina relevancia. Pensemos, además, en la importancia que adquiere su narración ante lo poco que él podía mostrar como fruto de su odisea. Se recordará que, al comparecer ante Carlos I, lo que lleva consigo Cabeza de Vaca era un trocito de piel de bisonte americano y algunas puntas de flechas de leve coloración cerúlea ${ }^{72}$.

En conclusión, al leerlo hoy, cuatrocientos cuarenta y cuatro años después de su publicación, el texto de Alvar Núñez nos atrae no sólo porque informa sobre culturas hoy desaparecidas, sino además porque sus páginas describen la consolidación de una escritura que él rescató de su propia memoria para gradualmente hacerla portadora de una articulación conflictiva de mecanismos retóricos; mecanismos que por sí mismos confirman la relevancia histórica y literaria de los Naufragios. Casi en todo momento, escribir se convertiría en parte fundamental de la saga de Núñez; pero es-

69 Subrayado es mío.

70 Subrayado es mío.

71 Es de interés la descripción que sobre ese nombramiento y los infortunios de Cabeza de Vaca ofrece Samuel E. Morrison, op. cit., pp. 516-536.

72 Ibid., p. 569. 
cribir será una actividad especialmente ardua a medida que él reflexiona sobre el significado de sus acciones y las consecuencias de éstas. Al tomar conciencia moderna, por así decirlo, de sí mismo como protagonista histórico, la relación que él mantendrá con sus propios escritos se hará problemática e indefinida ${ }^{73}$. El suyo es un texto que en algunos pasajes alcanza su mayor expresividad en la omisión y en un delicado margen de ambigüedad que se amplifica al ser detectado. Al hacer esa afirmación no he querido inferir que esos rasgos sean necesariamente el resultado de una deliberada elaboración de sus páginas. Aludo, más bien, a las omisiones que imponía tácitamente el marco ético e institucional de su época, y de modo especial la ambigüedad en su texto acaso deriva de olvidos y vivencias lingüísticas y culturales que a duras penas podían resumirse en el castellano del siglo xvi que alcanzó Cabeza de Vaca. Por ser así, en los Naufragios suelen destilarse cuidadosamente aspectos disímiles del proceso descriptivo; es esa acción la que permite, por ejemplo, que la contemplación y notaciones punzantes sustituyan a las generalizaciones o a la formulación abstracta ${ }^{74}$.

Después de años extraviado en la prehistoria, y tras haber sobrevivido rigores indecibles entre algunas de las tribus más desposeídas de Norteamérica, Alvar Núñez llegará a Nueva España. Concluía así un alucinante itinerario que le llevó de la cultura renacentista a la barbarie indócil del paleolítico americano. Esa es la otra trayectoria, no menos ardua, que él recorrió; y es a ese viaje, configurado por incontables regresiones culturales, al que rara vez aludimos, tal vez porque aún nos sobrecoge su delirante irrealidad. Finalmente, para dar mayor consistencia a su desastrado acontecer, el regreso de Cabeza de Vaca a Nueva España se nos revelará como una de las últimas contradicciones que encierran los Naufragios. Lo veo así porque su retorno fue, a la vez, oca-

73 Los datos que he recopilado sugieren que Núñez no logró un manuscrito satisfactorio de los Naufragios, ya que aun cuando regresaba prisionero del Paraguay traía consigo otra versión de su famoso relato, que ya se había editado en 1542. Véase Enrique Gandía, De la Torre del Oro a las Indias (Buenos Aires: Ediciones Rosso, 1935). Transcribe Gandía en su estudio un testimonio levantado en Asunción del Paraguay en que se enumeran las míseras posesiones del gobernador al ser enviado con griilos a España. «Un par de guantes blancos, una xeringa de metal y otros objetos semejantes, un testamento del dicho gonernador, un libro de memorias, un cuaderno de [genealogía] de los vera, un libro de mano de la relación de la florida» (sic), p. 128.

${ }^{74}$ En ese plano sus precisiones sobre la homosexualidad entre indígenas son un ejemplo de especial interés (Cap. XXVI). 
sión de júbilo, pero también de nuevas incertidumbres. Núñez había conocido el Nuevo Mundo en el simple trajín de puertos e improvisadas exploraciones que se iniciaron en Andalucía y continuaban en las Antillas. Pero al adentrarse en Nueva España conocerá una sociedad virreinal e institucionalizada donde ya eran otras las reglas del juego. En ese y otros sentidos, su retorno - como el de Ulises, Segismundo, Juan Preciado y tantos otros- también será la confirmación de lo enigmático en aquello que dábamos por conocido ${ }^{75}$. Son estas y otras analogías las que inscriben los Naufragios - para el lector de hoy- en una referencialidad literaria que inevitablemente expande las posibilidades de nuestras lecturas del texto ${ }^{76}$. No me parece exagerado agregar que después de las precisiones of recidas en estas páginas sería un equívoco insostenible identificar los Naufragios simplemente como otra crónica de Indias. Lo afirmo así porque en el texto de Núñez no suelen multiplicarse el embrollo de datos que a menudo obsesionó al cronista. Por el contrario, en su escritura prevalece una disposición paradigmática del acontecer que se revela en varios episodios y codificaciones que he subrayado: las que distingo son instancias que más de una vez sobrevuelan las prerrogativas humildes de la constatación fáctica. Recordemos, por último, que los Naufragios ha retenido la configuración siempre indecisa de un texto inconcluso, y también es cierto que el texto no siempre escapa a las asechanzas de lo pedestre y de la torpeza expositiva, pero más allá de esas limitaciones hay en las páginas de Alvar Núñez un régimen descriptivo cifrado en la omisión, el azar y en hiato vivencial, que enriquece la escritura por encima de lo que puedan revelarnos los rigores de la verificación empírica.

75 En este orden son oportunas las reflexiones de Mircea Eliade sobre la regeneración continua del tiempo, destino e historia que aparecen en su conocida obra El mito del eterno retorno (Madrid: Alianza Editorial, 1972), pp. 72, 122-128.

76 El motivo de la profecía, que aparece en el último capítulo, lo he comentado en mi introducción a la edición crítica del texto que publicará la Editorial Castalia. En otro estudio que en breve daré a conocer me ocupo, en detalle, de la configuración global de los Naufragios. 
